\title{
Demographic Objections to Epistocracy: A Generalization
}

\author{
Sean Ingham and David Wiens \\ (Forthcoming in Philosophy \& Public Affairs)
}

\begin{abstract}
Several scholars have recently entertained proposals for "epistocracy," a political regime in which decision-making power is concentrated in the hands of a society's most informed and competent citizens. These proposals rest on the claim that we can expect better political outcomes if we exclude incompetent citizens from participating in political decisions because competent voters are more likely to vote "correctly" than incompetent voters. We develop what we call the objection from selection bias to epistocracy: a procedure that selects voters on the basis of their observed competence-as epistocracy does-will often be "biased" in the sense that competent voters will be, on average, more likely than incompetent voters to possess certain attributes that reduce the probability of voting correctly. Our objection generalizes the "demographic objection" discussed in previous literature, showing that the range of realistic scenarios in which epistocracy is vulnerable to selection bias is substantially broader than previous discussions appreciate. Our discussion also shows that previous discussions have obscured the force of the threat of selection bias. Since we lack reasons to believe that epistocratic proposals can avoid selection bias, we have no reason to seriously entertain epistocracy as a practical proposal.
\end{abstract}




\section{Introduction}

Most democratic citizens appear to be ignorant of crucial facts about the political systems in which they participate, the parties and candidates they vote for, and the policies their leaders enact. ${ }^{1}$ They lack the basic knowledge one would need to form reliable judgments about politics. Some scholars trace democracy's ills to these well-known facts about "voter incompetence."2 Echoing Plato's critique of democracy and Mill's arguments for plural voting, some critics go further to entertain proposals for "epistocracy," a non-democratic regime in which the demonstrably "incompetent" are disfranchised or their decision-making power severely curtailed. ${ }^{3}$

\footnotetext{
${ }^{1}$ Predecessors of this paper were presented at the PPE Society Annual Meeting and at a seminar at New York University; we are grateful to these audiences for productive discussion. For detailed discussion, we are especially grateful to Dimitri Landa, Ryan Pevnick, and Melissa Schwartzberg. We also thank two anonymous referees at Philosophy \& Public Affairs for helpful suggestions.

${ }^{2}$ See, e.g., Christopher Achen and Larry Bartels, Democracy for Realists (Princeton, NJ: Princeton University Press, 2016); Bryan Caplan, The Myth of the Rational Voter (Princeton, NJ: Princeton University Press, 2007); Joseph Schumpeter, Capitalism, Socialism, and Democracy (New York: Harper, 1942); Ilya Somin, Democracy and Political Ignorance: Why Smaller Government is Smarter (Palo Alto, CA: Stanford University Press, 2013).

3 Jason Brennan, Against Democracy (Princeton: Princeton University Press, 2016); Adam F. Gibbons, "Political Disagreement and Minimal Epistocracy," Journal of Ethics and Social Philosophy, 19 (2021): 192-201; Thomas Mulligan, "Plural voting for the twenty-first century," The Philosophical Quarterly 68 (2018): 286-306. Cf. Garrett Jones, 10\% Less Democracy: Why You Should Trust Elites a Little More and the Masses and Little Less (Palo Alto, CA: Stanford University Press, 2020); Claudio López-Guerra, Democracy and Disenfranchisement: the Morality of Electoral Exclusions (New York: Oxford University Press, 2014); Finlay Malcolm, "Epistocracy and Public Interests," Res Publica (forthcoming), https://philpapers.org/rec/MALEAP-2, accessed
} 
Arguments for epistocracy are instrumental: they rest on the claim that we can expect better political decisions - and, in turn, better political outcomes-if we exclude incompetent citizens from participating in political decisions. As Brennan puts it, "there are [...] good grounds to presume that some feasible form of epistocracy would in fact outperform democracy."4 The grounds for this expectation seem highly intuitive: starting from an ostensible platitude- that a voter can be expected to make good decisions only if they have certain knowledge and abilities - it seems a short step to the claim that a decision-making body that excludes incompetent people should be more likely to make "good" or "correct" decisions than a decision-making body that includes competent and incompetent alike.

Various objections have been raised against epistocracy. One familiar argument is, in effect, that the epistocrat's "short step" commits the fallacy of composition. As epistemic democrats often point out, groups can have a higher likelihood of producing correct decisions than we might expect from looking at the average competence of the individual members of the group, owing to the mechanisms used to aggregate individuals' contributions to the group's decision-making procedure. ${ }^{5}$ These arguments target the inference from the claim that competent individuals are more likely to choose correctly than incompetent individuals to the claim that groups largely composed of competent individuals are more likely to choose correctly than groups composed of both compeMay 3, 2021.

${ }^{4}$ Brennan, Against Democracy, p. 16.

${ }^{5}$ For example, Robert E. Goodin and Kai Spiekermann, An Epistemic Theory of Democracy (Oxford: Oxford University Press, 2018); Hélène Landemore, Democratic Reason: Politics, Collective Intelligence, and the Rule of the Many (Princeton, NJ: Princeton University Press, 2012). For additional reasons to distinguish between claims about voters and claims about electorates, which are distinct from those emphasized by epistemic democrats, see Scott Ashworth and Anthony Fowler, "Electorates versus Voters," Journal of Political Institutions and Political Economy 1 (2020): 477-505. 
tent and incompetent individuals. Whatever the merits of these arguments, we focus our attention elsewhere. $^{6}$

We develop what we call the objection from selection bias, which generalizes a class of objections previously discussed as "the demographic objection" to epistocracy. ${ }^{7}$ As we present it, this objection targets the claim that competent voters are, on average, more likely to vote correctly than incompetent voters; or, put differently, that competence is correlated with a higher probability of voting correctly. In the first instance, epistocrats might infer this claim from the assumption that a certain kind of competence increases one's probability of voting correctly. We show that this inference is faulty because it ignores the realistic possibility that (put roughly for now) the explanation for why some people acquire competence also implies that competence is positively correlated with attributes that decrease the probability of voting correctly. Where this possibility is realized, any procedure that selects voters on the basis of their observed competence will be "biased" in the sense that competent voters will be, on average, more likely than incompetent voters to possess certain attributes that reduce the probability of voting correctly. Thus, competent voters may be less likely to vote correctly than incompetent voters even though competence increases one's probability of voting correctly. Recognizing this inferential error, epistocrats might try arguing directly for the claim that competence is correlated with a higher probability of voting correctly. However, the reasons to expect bias in a procedure for selecting competent voters imply

${ }^{6}$ We also set aside doubts about whether it is possible to have the kind of knowledge that epistocrats propose to make a condition for enfranchisement; see, e.g., Paul Gunn, "Against Epistocracy," Critical Review 31 (2019): 26-82; Julian Reiss, "Expertise, Agreement, and the Nature of Social Scientific Facts, or: Against Epistocracy,” Social Epistemology 33 (2019): 183-92.

${ }^{7}$ Jason Brennan, “Does the Demographic Objection to Epistocracy Succeed?" Res Publica 24 (2018): 53-71; David Estlund, Democratic Authority: A Philosophical Framework (Princeton: Princeton University Press, 2008), chap. 11; Thomas Mulligan, “On the compatibility of epistocracy and public reason," Social Theory and Practice 41 (2015): 458-476. 
that any argument for that claim must rest on premises that are, at best, highly speculative and, at worst, deeply implausible. Without any reasons to accept the claim that competent voters are more likely to vote correctly than incompetent voters, we have no grounds for expecting that epistocratic decision procedures will tend to produce better decisions than democracy with universal suffrage.

Previous discussions of the demographic objection have obscured both the scope and the force of the threat that selection bias poses to arguments for epistocracy. Regarding scope, the range of realistic scenarios in which epistocratic proposals are threatened by selection bias is substantially broader than extant discussions appreciate. This is because these discussions have neglected the broader implications of candidate explanations for the distribution of competence within a population.

Previous discussions have also misconstrued the force of the threat of selection bias because they have assumed the upshot of the demographic objection to be the conclusion that democracy with universal suffrage is better than epistocracy. As we present it, however, the objection from selection bias does not provide a reason to endorse universal suffrage. Without a direct measure of who is voting "correctly," and absent heroic assumptions about how all the myriad influences on voting behavior are jointly distributed within a population, there is no way to draw a conclusion about whether the typical voter in an epistocracy would be more or less likely than the typical democratic voter to vote correctly. That is the point of our objection. As we see it, then, the threat of selection bias implies a skeptical claim: namely, that we have no reason to expect that the average epistocratic voter will be more likely to vote correctly than the average democratic voter. So far as we can tell, epistocrats have grounded their proposals on little more than this expectation. Absent any reason to hold it, however, we lack any reason to seriously entertain epistocracy as a practical proposal. 


\section{Preliminaries}

The objection from selection bias is directed against epistocratic proposals to restrict voting rights to citizens who possess some desirable form of competence. Proposals for more complicated forms of epistocracy, and their potential vulnerability to the objection, are considered in a later section. To state the objection we need to define some terms.

An epistocratic suffrage rule is an institutional rule that grants voting rights to citizens who demonstrate knowledge or abilities that, by assumption, increase a voter's probability of voting correctly. Call this bundle of knowledge and abilities, whatever it might be, measurable competence. We leave it to epistocrats to specify this further, whether it be the knowledge measured by performance on a "voter qualification exam", 8 a university degree, ${ }^{9}$ or some other kind of knowledge or ability that is empirically measurable and increases the probability of voting "correctly." A person votes correctly if they vote for whichever option is best, according to whatever standard (justice, the common good, etc.) epistocrats propose to use to make the argument that epistocracy would produce better decisions than democracy. ${ }^{10}$ An epistocratic electorate is a group of people who are eligible to vote under an epistocratic suffrage rule, and a democratic electorate is a group of people who are eligible to vote under a standard rule of universal suffrage.

Those who sympathetically consider epistocratic suffrage rules argue they would produce better decisions than universal suffrage. This conclusion seems to be based on the belief that the average probability of voting correctly among members of an epistocratic electorate is higher than

\footnotetext{
${ }^{8}$ For example, Brennan, Against Democracy, pp. 211-12.

${ }^{9}$ For example, John Stuart Mill, Considerations on Representative Government (New York: Cambridge University Press, 2010), chap. 8.

${ }^{10}$ For the sake of simplicity, we restrict attention to binary political decisions, such as elections between two candidates or referendums on ballot measures. We also bracket questions about the agenda-setting process, important as they are.
} 
the average probability of voting correctly among members of a democratic electorate. This belief is the focus of our argument: are there any reasons to believe the average epistocratic voter is more likely to vote correctly than the average democratic voter?

Our question presupposes a concrete and feasible implementation of an epistocratic suffrage rule. The rule with which we compare universal suffrage must not be defined abstractly as the rule that enfranchises all and only those citizens who are most likely to vote correctly, or-worse yetthe rule that maximizes the probability that the electorate makes the best decision. Such suffrage rules would make the answer to our question trivial. Brennan gives a less extreme but still problematic description of epistocracy: "a system is epistocratic to the extent that greater knowledge and the good faith to act on this knowledge are de jure, legal prerequisites for holding power or are legal grounds for being granted greater power through law."11 This describes an aspiration rather than an institution. Knowledge and the good faith to act on it cannot be perfectly observed; at best, an institutional designer could aspire to design rules that would reliably but imperfectly make voting rights conditional on knowledge and good faith. These aspirational suffrage rules force us into an unfair comparison, pitting concrete democratic procedures against epistocratic proposals that lack any determinate institutional embodiment. Our approach will be, instead, to posit some feasible test for reliably but imperfectly assessing competence, hold this test fixed, and then compare the probability that the typical democratic voter will vote correctly with the probability that the typical epistocratic voter will vote correctly.

A second point to make about our question concerns an ambiguity in the comparison it asks about. To see this, fix a population of citizens, all of whom would be enfranchised under universal suffrage, and assume that, in actual fact, democratic voting rules with universal suffrage are in place. Even when passing a competence test is not a condition for voting, some of these citizens have acquired or will acquire the information or abilities that would, hypothetically, allow them to pass a competence test were it to be administered. We could compare the average probability

\footnotetext{
${ }^{11}$ Brennan, "Does the Demographic Objection to Epistocracy Succeed?", p. 54.
} 
of voting correctly within this group with that of the general population. Alternatively, we could consider the counterfactual scenario in which the competence test has been instituted and then compare the average probability of voting correctly for this counterfactual epistocratic electorate with the average probability of voting correctly for the democratic electorate. The second comparison, but not the first, is sensitive to any possible treatment effects of instituting the exam-some people who would fail the competence test when actual institutions are democratic might be incentivized to behave differently, and might therefore pass the exam, if the exam were put in place as a condition for voting. For this reason the second comparison appears more directly relevant to a comparative assessment of democracy with epistocracy. Hereafter, "epistocratic electorate" refers to the group of voters who would pass a competence test were one implemented as a condition for voting, and "epistocratic voter" refers to a member of this group.

Finally, note that our question compares the average epistocratic voter with the average democratic voter, rather than comparing the epistocratic electorate with the democratic electorate. We are thereby bracketing familiar questions concerning aggregation that are no doubt relevant to a comprehensive assessment of democratic and epistocratic voting procedures. ${ }^{12}$ Epistocrats have not appealed to any mechanisms of this kind so, given our purposes, it is appropriate to set these issues aside.

\section{The objection from selection bias}

The objection from selection bias targets the following

Epistocratic Conjecture: The average epistocratic voter is more likely to vote correctly than the average democratic voter.

\footnotetext{
${ }^{12}$ Cf. Goodin and Spiekermann, An Epistemic Theory of Democracy; Landemore, Democratic Reason.
} 
Epistocrats don't provide empirical evidence for this conjecture. Doing so would require identifying which option is best (in some particular context) and then comparing the proportions of competent and incompetent voters who vote for it. Since there is reasonable disagreement about which options are best in most contexts, epistocrats understandably avoid burdening their arguments with controversial claims along these lines. ${ }^{13}$

Nor do epistocrats explicitly argue for the conjecture on theoretical grounds. As far as we can tell, the best reconstruction of epistocrats' reasoning is something like the following: ${ }^{14}$

(1) Being measurably competent increases a person's probability of voting correctly.

(2) Thus measurably competent citizens are more likely to vote correctly than measurably incompetent citizens.

(3) An epistocratic electorate has a greater proportion of measurably competent voters than a democratic electorate.

(4) Thus the average epistocratic voter is more likely to vote correctly than the average democratic voter.

The first premise is true by our definition of "measurable competence". The third premise is almost trivially true: all members of an epistocratic electorate have measurable competence, by definition, and it is unlikely that all members of a democratic electorate would. The critical step is the move from (1) to (2), which we show is a non sequitur.

${ }^{13}$ Brennan, Against Democracy, p. 19. Sean Ingham notes some difficulties with avoiding claims about which options are best in the context of epistemic arguments for democracy; Ingham, "Disagreement and Epistemic Arguments for Democracy," Politics, Philosophy \& Economics 12 (2013): 136-155.

${ }^{14}$ If there is a better argument available to epistocrats, we hope our critique provokes someone to clarify what it is. 
First, let's note that premise (1) is a statement about the causal effect of competence on an individual's probability of voting correctly. It does not say that someone who has measurable competence is, all things considered, more likely to vote correctly; that is, it does not say that measurable competence is correlated with a higher probability of voting correctly. That is what (2) asserts, and it is, in essence, the conjecture in dispute. Premise (1) compares an actual probability with a counterfactual probability — how much more (less) likely one would be to vote correctly if one were (in)competent, holding all other relevant variables constant—while (2) compares actual probabilities between two groups of voters, competent and incompetent.

Note also that premise (1) has a strong and a weak interpretation. On the strong interpretation, (1) says that competence increases everyone's probability of voting correctly-that the effect of competence is always positive. On the weak interpretation, (1) says that the average effect of competence is positive, which is consistent with saying that, for some people, competence makes no difference to the probability of voting correctly-for those of ill-will or otherwise morally corrupt character perhaps. Which interpretation is plausible will depend on which specific abilities and forms of knowledge are used to fill out the definition of "measurable competence". Since we leave this further specification to epistocrats, we also leave it to them to decide which interpretation of (1) they prefer. Our argument is consistent with either interpretation.

To see why the move from (1) to (2) is a non sequitur, consider an analogous inference:

(i) Statins reduce one's risk of cardiovascular disease (on average, they reduce one's risk).

(ii) Thus the average person taking statins is at lower risk of cardiovascular disease than the average person not taking statins.

Statement (i) is about the causal effect of taking statins on one's risk of cardiovascular disease, while statement (ii) asserts a correlation between taking statins and a decreased risk of cardiovascular disease. Like the move from (1) to (2), the move from (i) to (ii) infers a statement about a correlation between two variables from a statement about the causal effect of one variable on the 
other. This inference is faulty because the average person who takes statins differs from the average person who does not in numerous ways beyond their consumption of statins. The most important difference is that the average person taking statins has a greater "baseline risk" of cardiovascular disease — risk in the (counterfactual) scenario where they are not taking the medication—than the average person who does not take statins. This is why people choose to take the medication in the first place; people "self-select" into the treatment group on the basis of their baseline risk of disease. There is thus "bias" in the process of determining who ends up in which group. As a result, the group of people who take statins can have a higher average risk of cardiovascular disease than the group of people not taking statins even while each person who takes statins has a lower risk of cardiovascular disease than they would have without the medication.

Just as selection bias blocks the move from (i) to (ii), so selection bias blocks epistocrats' move from (1) to (2). That move is unwarranted unless one can defend the further claim that there is no significant selection bias in the process determining who ends up in the group of competent voters. The question, then, is whether we have compelling reasons to accept or reject this claim.

Selection bias occurs when "confounders" influence both the probability of ending up in the "treatment" group and, via other causal pathways not involving the treatment ("confounding pathways"), the outcome of interest. In our medical example, risk factors for cardiovascular disease lead people to take statins but also (by a different causal path) raise the risk of cardiovascular disease. In the political context, potential confounders would be any variables that influence both the probability of acquiring measurable competence and also, via other causal pathways not involving competence, the probability of voting correctly (see figure 1). To take just one example, suppose the measure of competence is knowledge of the candidates' positions on various issues, and that one is more likely to acquire this knowledge if one travels in more affluent social circles where such knowledge is esteemed as a sign of sophistication or good citizenship. Plausibly, membership in such affluent social networks affects various other attributes-e.g., cultural attitudes or ethical beliefs-which influence policy preferences and, in turn, voting behavior independently of com- 


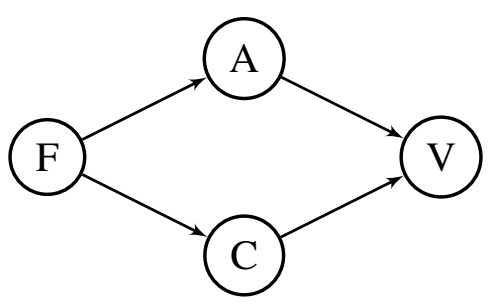

Figure 1: A factor $(\mathrm{F})$ increases the probability that a person will acquire competence $(\mathrm{C})$, which in turn affects voting behavior $(\mathrm{V}) ; \mathrm{F}$ also increases the probability that a person will possess some other attribute (A), which, depending on the attribute and the context, increases or decreases the probability of voting correctly. $\mathrm{F}$ is thus a confounder and $\mathrm{F} \rightarrow \mathrm{A} \rightarrow \mathrm{V}$ is a confounding pathway. $\mathrm{C}$ and $\mathrm{A}$ are systematically correlated, so that selecting for competence also indirectly selects for any attributes (A) that are causally downstream of the confounder.

petence. There are many more plausible candidates for confounding variables, some of which we discuss below. For any particular hypothesis about a source of selection bias, reasonable people might disagree about how much credence to put in it, but there are no a priori reasons for rejecting each and every one of these hypotheses.

Due to selection bias, then, the move from (1) to (2) is a non sequitur. Indeed, it is a non sequitur for reasons that are familiar to advanced undergraduates or first-year graduate students in the social sciences. It is a social scientific platitude that "correlation does not imply causation", that we cannot infer that one variable has a causal effect on another from the observation that the two variables are correlated. Such an inference is faulty due to the threat of selection bias. Selection bias implies that the converse is also true: "causation does not imply correlation". Epistocrats' move from (1) to (2) thus violates an elementary insight about causal inference.

For all we've said thus far, selection bias only blocks the move from (1) to (2); it doesn't imply that (2) is false. Since the Epistocratic Conjecture follows from (2) and (3) alone, epistocrats might look for ways of vindicating (2) without deriving it (solely) from (1). Might premise (2) be true despite the realistic threat of selection bias?

Epistocrats could add a premise that, together with (1), would imply (2). ${ }^{15}$ For instance, they

${ }^{15}$ Alternatively, epistocrats might be tempted to treat (2) as true by definition, simply defining 
could argue that any attributes correlated with competence do not (on average) decrease the probability of voting correctly or that any negative effect on the probability of voting correctly does not outweigh the positive effect of competence. One finds versions of an argument along these lines in existing discussions of the so-called "demographic objection". 16 These discussions consider the possibility that demographic variables such as race or class might play the role of confounders, with the confounding causal pathways involving some sort of bias or other moral or cognitive shortcoming. If this is all the objection from selection bias amounts to, then it might seem a manageable task to justify the additional premise: first, we identify the demographic variables that are correlated with competence; then, for each of these variables, we show that the biases of the members of each demographic group do not, on average, outweigh the positive effect of competence on the probability of voting correctly. This is, in effect, Brennan's reply to the demographic objection: he first fixes on self-interested voting as the mechanism that is mostly likely to produce decisions biased in favor of epistocratically-privileged demographic groups; he then argues that voters do not—not on average, anyway—engage in self-interested voting. ${ }^{17}$ Thus, he concludes that any biases we might find in an epistocratic electorate do not, on average, outweigh the positive effect of competence on the probability of voting correctly.

The range of potential confounding pathways is much broader and much more difficult to dismiss than those considered in the existing literature, however. Any argument meant to show that (2) is true must rest on premises that are, at best, highly speculative and, at worst, deeply implausible, depending on the context. To illustrate this point, we consider examples of two kinds of confounders: those that generate systematic differences in people's opportunities for acquiring "competence" as that bundle of abilities and knowledge that is correlated with a higher probability of voting correctly. We comment on this move in the conclusion.

16Brennan, "Does the Demographic Objection to Epistocracy Succeed?"; Estlund, Democratic Authority; Mulligan, "On the Compatibility of Epistocracy and Public Reason”.

${ }^{17}$ For example, Brennan, “Does the Demographic Objection to Epistocracy Succeed?”, p. 66. 
competence, and those that generate systematic differences in their motives to take advantage of those opportunities. These examples clarify why the realistic threat of selection bias poses serious difficulties for any argument for premise (2).

Opportunities for training. The first type of confounder consists of variables that affect one's opportunities for cultivating and training the abilities that constitute (part of) measurable competence. The demographic variables previous theorists have considered in the context of the demographic objection fall into this category. The conditions under which they will play the role of confounders are more general than previously appreciated, however.

A university education is an example of an opportunity to cultivate certain cognitive abilities and habits of mind that may improve one's prospects of enfranchisement under an epistocratic suffrage rule. In many contexts, demographic variables like race and gender affect the probability that a person will have these opportunities; so, too, can variables such as household income, the educational attainment of one's parents, and one's physical and mental health. These characteristics thus affect one's probability of acquiring measurable competence. But they also affect voting behavior via pathways that do not involve competence acquisition; for example, by affecting how one perceives the relationships between various policy issues and one's well-being and sense of belonging, or by affecting the composition of one's social group and, in turn, a range of social influences on one's policy preferences (e.g., which sources of information one considers trustworthy).

To take one of Brennan's suggestions, suppose the voter competence exam measures knowledge of economics, assuming that knowledge of economics either causes one to be more likely to vote correctly or is a proxy for knowledge that has this effect. Let's suppose that a person with a university degree will be more likely to have cultivated the abilities needed to pass the proposed competence exam. Imagine that, owing to a history of racial hierarchy and oppression, members of the dominant racial group are more likely to have opportunities to attend university and, hence, more likely to acquire a university degree. Competence is thus correlated with race. Now sup- 
pose that in a given election, Party A is the "correct" option. Suppose further that Party B has a checkered history of tolerating or encouraging racial division.

In previous discussions of the demographic objection, this story continues by positing that membership in the privileged racial group leads to racial prejudice and thereby to sympathy for the party that appeals to racial prejudice, thus reducing the probability of voting correctly. This mechanism could produce the result that those who are measurably competent are less likely to vote for the best option than those who lack measurable competence. Premise (2) fails to hold in this case.

The familiar version of the story is only one possibility. To form a reasonable belief about the plausibility of (2), given that race is correlated with competence, it is important to consider alternative confounding pathways from race to voting behavior. For instance, in another plausible version of the story, members of the minority racial group are "biased" against Party B, in the sense that their suspicion toward Party B (even if it is entirely justified by the party's history) reduces the probability that they will vote for Party B, irrespective of which party is the best option in the present circumstances. As a result, majority racial status is correlated with a lower average probability of voting for Party A and, so, this mechanism could also produce the result that those who are measurably competent are less likely to vote for the best option than those who lack measurable competence. Premise (2) again fails to hold. Or consider a third continuation of the story, in which racial status affects a person's future occupation and social class and, in turn, voting behavior. For example, members of the minority racial group may be more likely to work in unionized workplaces and as a result become more sympathetic to Party A because of its historical association with labor movements. This, too, could produce the result that measurably competent citizens are less likely to vote for the best option. Yet again, premise (2) fails to hold. ${ }^{18}$

In the second and third versions of the story, majority racial status is a confounder that in-

${ }^{18}$ This last mechanism could be instantiated using different confounders; variables like household income and parents' educational attainment might play a role similar to that of race. 
creases the probability of acquiring measurable competence and reduces the probability of voting for Party A, but not because it leads to self-interested or prejudicial voting on the part of those who acquire measurable competence. The confounding pathway does not involve any moral or cognitive shortcomings in those who acquire measurable competence. Instead, it explains why those who are less likely to acquire measurable competence are more likely to be biased in favor of the correct option. ${ }^{19}$ The confounder does not "robustly" reduce the probability of voting for the correct option, whatever the correct option is. Instead, it reduces the probability of voting for the correct option for contingent reasons unrelated to the reasons explaining why it is the correct option.

This last observation might prompt the reply that, if it is only for contingent reasons that measurable competence is associated with a reduced probability of voting correctly, then the example does not illustrate a general reason for rejecting (2). But that conclusion is mistaken: the threat of selection bias implies that, where measurable competence is correlated with an increased probability of voting correctly (as premise (2) maintains), it is only contingently so. To see why, suppose it is true of our example that competence is correlated with a higher probability of voting for Party A. Since the previous paragraph shows that, plausibly, this might not have been so, the explanation for this correlation must appeal to contingent facts about the joint distribution (within the population) of various attributes-including competence-that are both causally downstream from race and influence voting behavior. Generally speaking, then, our example illustrates that the truth of (2) can only be determined on a case-by-case basis. Whether (2) is true depends on: (a) which variables systematically influence the distribution of opportunities for acquiring competence (race is

${ }^{19}$ Other confounding pathways from race to voting behavior emerge once we recognize that university graduates can systematically differ from non-graduates in myriad ways beyond average competence; for example, they might have higher average incomes or be more likely to favor leftleaning social policies (perhaps, as conservatives are wont to point out, due to the widespread "liberal" socialization that occurs on university campuses). 
only one example); (b) which attributes are causally downstream of those opportunity-influencing variables; and (c) the direction and magnitude of the effect of these attributes on the probability of voting for the correct option across the set of determinate choices an electorate is likely to face. Epistocrats have provided no compelling theoretical reasons to expect that this mass of contingent facts will tend to align so that premise (2) holds more often than not; nor have they presented arguments to ground a theoretical expectation about the contingent conditions under which (2) is likely to be true. And, absent controversial assumptions about which options are best across a sufficiently broad range of determinate choices, they cannot provide empirical evidence that these contingent facts support (2). Thus, reflecting on the reasons to expect selection bias, it is clear we have no reason to accept (2) as a general truth. Without that premise, we have no reason to accept the Epistocratic Conjecture.

Motives to acquire competence. The previous examples focus on systematic differences in opportunities for acquiring competence as a source of selection bias. We now focus on systematic differences in motivation to acquire competence, a source of selection bias that would plausibly be present even in hypothetical societies where everyone has the same opportunities for acquiring competence.

To take another of Brennan's examples, suppose that the competence exam measures, not knowledge of an academic field such as economics, but basic knowledge about the candidates and their positions. Almost all citizens in established democracies now have abundant opportunities to acquire this kind of basic information but few choose to become well-informed. From a familiar point of view, what requires explanation is not why so many citizens are ignorant of these matters, but rather why a select few choose to spend time and energy acquiring such information. The probability of casting a vote that changes the election outcome is effectively zero, so the consequences of casting an ill-informed vote provide little motivation to become informed. What is perhaps surprising, then, is that some people nonetheless become well-informed. 
Critics who emphasize the problem of voter ignorance (e.g., Brennan, Caplan, Somin) are familiar with this observation, which is rhetorically useful when the goal is to explain why we should view the typical democratic citizen's ignorance as more or less inevitable - a product of incentives that would be present in any realistic democracy_rather than a remediable and contingent defect of actually existing democracies. But these critics neglect its implications when discussing the demographic objection to epistocracy.

Suppose (plausibly enough) that some citizens have ideological or partisan motivations for acquiring information. They may find it gratifying to acquire information that confirms their antecedently held political opinions, or they may reap social benefits from being able to publicly marshal "evidence" in support of their antecedently held opinions. For convenience, call citizens of this type ideological voters. ${ }^{20}$ And suppose, for simplicity, that most other citizens are apathetic voters: they have no entrenched partisan allegiance or firmly held political opinions that are integral to their sense of self and identity but, for this reason, they also lack the ideological voter's instrumental reasons for becoming well-informed. Information will not flatter their sense of superiority or confirm their sense of self, nor do they need to arm themselves with information for partisan combat, which they have no desire to engage. Without prejudices standing in the way, information might make a difference to these voters' political opinions; but lacking ideological prejudices they feel the need to rationalize for personal or social reasons, they have no incentives to acquire information. ${ }^{21}$ When the population consists largely of these two types, requiring citizens to pass a test measuring knowledge of the parties and their positions will be an indirect means of selecting for ideological voters. As a result, epistocratic voters will be more likely to be ideological voters than democratic voters.

In this scenario, ideological motivation is a confounder-it influences both the probability a voter acquires measurable competence and, via causal pathways not involving competence, the

${ }^{20}$ Compare with Brennan's political "hooligan” in Against Democracy, p. 5.

${ }^{21}$ Compare with Brennan's description of "hobbits" in Against Democracy, p. 4. 
probability of voting correctly. To fix ideas about a plausible confounding pathway, let's assume ideological motivation increases the probability of consuming information in an ideologically biased manner. If biased information consumption has a negative causal effect on the probability of voting correctly and the size of this effect is large enough, then, because measurable competence is (by hypothesis) correlated with biased information consumption, measurably competent voters can be less likely to vote correctly than apathetic voters, and premise (2) will be false.

Ideological motivation could be a confounder in either of two ways, "robustly" or "contingently." Regarding the former, we might plausibly imagine that everyone has some basic ability to "track" facts about which options are best—in the sense that such facts affect their beliefs about which option is best-but that biased information consumption interferes with this ability, making the ideological voters worse truth-trackers than the apathetic voters. This would make ideological motivation a "robust" confounder: by increasing the probability of biased information consumption, it reduces the probability of voting correctly whatever the correct option is, even while it increases the probability of acquiring the kind of competence that the exam measures (information about the candidates and their policies).

To see how ideological motivation can be a contingent confounder, suppose apathetic and ideological voters are equally bad at tracking facts about which options are best. For simplicity, let's assume the extreme case in which no one is doing any tracking-facts about which options are best are causally inert. Yet, for contingent reasons, apathetic voters (in the baseline scenario where they lack information) tend to support Party A, which happens to be the better option for unrelated reasons, while ideological voters (in the baseline scenario) are by comparison more likely to support Party B. Why might this kind of scenario be plausible? One explanation is that Party B could be more successful at inflaming the ideological passions of its supporters such that ideological thinking (via its positive effect on biased information consumption) correlates with voting for Party B. In such a scenario, ideological thinking is a contingent confounder, but a confounder all the same. Due to selection bias, then, those voters who acquire measurable competence can be less likely to 
vote correctly than those who lack it.

Ideological motivation is just one source of systematic differences in individuals' eagerness to acquire information. We can easily imagine others. There is evidence that some of the "Big Five" personality traits, such as conscientiousness, influence years of schooling, grades, and scores on tests of cognitive ability, ${ }^{22}$ and it would not be surprising if they also turned out to influence (either directly or through their effects on educational outcomes) success on a test of political competence. An independent literature in political science argues that these traits influence political attitudes as well; for example, one finding is that conscientiousness is associated with conservatism, at least in certain political contexts. ${ }^{23}$ This suggests another possible source of selection bias that an argument for the epistocratic conjecture would have to rule out: namely, the possibility that certain personality traits both increase the probability of acquiring measurable competence and, by other causal pathways, predispose people to ideological orientations that, perhaps only contingently if not robustly, reduce the probability of voting correctly. Yet another possibility, to which we alluded above, is that some people have social incentives to acquire information-a desire "to belong to and be respected by some group" whose members value knowledge about politics. ${ }^{24}$ Those incentives may also be associated, in complicated ways, with class, education, or other demographic variables. These latter variables may not robustly reduce the probability of voting correctly, but they may influence voting behavior, and, for the reasons enumerated above, that possibility suffices to undermine our confidence that premise (2) is generally true, or even true in a wide enough range

${ }^{22}$ For an overview of the literature, see Mathilde Almlund, Angela Lee Duckworth, James Heckman, and Tim Kautz. "Personality Psychology and Economics." In Handbook of the Economics of Education, volume 4 (Elsevier, 2011), pp. 1-181.

${ }^{23}$ Alan S. Gerber, Gregory A. Huber, David Doherty, Conor M. Dowling, and Shang E. Ha, "Personality and Political Attitudes: Relationships across Issue Domains and Political Contexts," American Political Science Review 104(1) (2010): 111-133.

${ }^{24}$ Brennan, Against Democracy, p. 35. 
of contingent conditions to warrant support for epistocratic suffrage rules.

\section{Selection bias and the demographic objection}

As we have developed it, the objection from selection bias generalizes and subsumes the "demographic objection" to epistocracy discussed in previous literature. ${ }^{25}$ But these previous discussions obscure both the scope and the force of the objection.

Regarding the scope of the objection, our examples in the previous section show that the range of realistic scenarios in which epistocratic suffrage rules are vulnerable to selection bias is considerably broader than extant discussions of the demographic objection have appreciated. In particular, our examples show that the range of confounding variables is not limited to observable demographic attributes but also includes unobservable (or hard-to-observe) attributes such as ideological motivation or a desire to "fit in" with certain social groups. Additionally, our examples show that the range of plausible confounding pathways is not limited to the activation of certain moral or cognitive shortcomings such as racial prejudice or self-interest. ${ }^{26}$ Extant discussions of the demographic objection have obscured the scope of the objection because they have neglected to reflect on the reasons why some people acquire the information or skills that a competence exam would measure. But there is no way to form a reasonable opinion about the plausibility of premise (2) and, in turn, the Epistocratic Conjecture without first engaging in that reflection. The distribution of competence within a population cannot be taken as given but is something to be explained. Once we survey plausible explanations for the distribution of competence, we realize that many of the variables that influence the distribution of competence also influence the distribution of other

${ }^{25}$ Brennan, "Does the Demographic Objection to Epistocracy Succeed?"; Estlund, Democratic Authority; Mulligan, "On the Compatibility of Epistocracy and Public Reason”.

${ }^{26}$ Cf. Brennan, "Does the Demographic Objection to Epistocracy Succeed?"; Estlund, Democratic Authority. 
variables that, in turn, affect voting behavior. Faced with this realization, the only reasonable belief is that epistocratic suffrage rules are vulnerable to selection bias in a way that makes the truth of premise (2) highly contingent on the joint distribution of all these variables within a population. Epistocrats have given us no reason to believe otherwise.

Previous discussions also obscure the force of the objection from selection bias. For example, Brennan reconstructs the demographic objection as implying the strong claim that epistocratic decision procedures will produce worse results than democratic decision procedures. ${ }^{27}$ Yet, properly understood, the objection from selection bias implies no such thing. The point is, instead, that we have no reason to accept premise (2) as a general truth. The upshot is that we have no reason to accept the Epistocratic Conjecture. Since arguments for epistocratic suffrage rules rest entirely on the Epistocratic Conjecture, the objection from selection bias implies that we have no reason to expect that epistocratic suffrage rules are likely to produce better results than universal suffrage.

This weaker claim—namely, that we have no reason to accept the Epistocratic Conjectureis enough to put to rest serious discussion of epistocratic suffrage rules as a practical proposal. The reasons to entertain such rules are only as good as the reasons for expecting that they would produce better decisions than universal suffrage. There are no other serious claims to be made on their behalf. Allocating political power according to measures of competence is not intrinsically desirable. If there are in fact no reasons to expect the typical epistocratic voter to be more reliable than the typical democratic voter, then epistocratic suffrage rules do not merit serious practical

27 “Does the Demographic Objection Epistocracy Succeed?", p. 63. More precisely, Brennan calls this the "bad results" version of the demographic objection. He also presents an "unfairness" version, according to which it is unfair to exclude members of some demographic groups from political power. We ignore this version because it represents an idiosyncratic understanding of the demographic objection by setting aside concerns about the decision-making consequences of competence being correlated with certain demographic variables, which are central to typical statements of the demographic objection. 
consideration.

Whereas Brennan overstates the upshot of the threat of selection bias, Estlund understates it. As Estlund states it, the demographic objection (which he lodges against Mill's scheme for plural voting) is a version of the objection from selection bias, focusing specifically on the potential association of education with "epistemically damaging" features. ${ }^{28}$ In his initial statement, Estlund posits certain demographic variables such as race and class as potential confounders, which explain the association of education with characteristics (e.g., racial or class bias) that damage a voter's epistemic quality. After considering the possibility that voting weights might be adjusted so as to correct for the underrepresentation of socially disadvantaged groups among the educated, he considers a revised version of the objection, which posits "latent" and "conjectural" characteristics that might be correlated with education but damage a voter's epistemic quality. As Estlund sees it, the demographic objection ultimately rests on the possibility that "there may remain important sample errors [i.e., selection bias] of which we are unaware" even if a plural voting scheme restricts the allocation of extra votes to a demographically representative sample of educated citizens. What are we to make of this concern? While Estlund refrains from endorsing the objection on its merits, he concedes that the concern is "not crazy" and therefore surmises it may be reasonable enough to defeat the claim that an "epistocracy of the educated" is legitimate. ${ }^{29}$

By contrast, we do not hold that the objection from selection bias is one that a reasonable person might endorse, while remaining ourselves agnostic. We endorse it without reservation, as ought the reader. Estlund's equivocal stance on the force of the demographic objection is at least partly explained by the fact that he introduces it to support the claim that the average epistocratic voter is less likely to vote correctly than the average democratic voter. But this claim is logically stronger than the claim that the objection from selection bias can support: namely, that we have no reasons to believe that the average epistocratic voter will be more likely to vote correctly than the

${ }^{28}$ Democratic Authority, pp. 215-19.

${ }^{29}$ Ibid., p. 218. 
average democratic voter. ${ }^{30}$ Since this skeptical claim clearly follows from the fact that epistocratic suffrage rules are vulnerable to selection bias, we have no reason to hedge our endorsement of the objection.

\section{Institutional patches to epistocracy}

Brennan acknowledges that competence, by whatever operative measure, will be correlated with various demographic variables. ${ }^{31}$ One of his responses is to propose versions of epistocracy that are allegedly not susceptible to the demographic objection. One involves the use of an enfranchisement lottery, first introduced by López-Guerra; the other is what Brennan calls Government by Simulated Oracle. ${ }^{32}$

Government by Simulated Oracle institutionalizes a simulation of the electorate's counterfactual "enlightened" preferences:

We can administer surveys that track citizens' political preferences and demographic characteristics, while testing their basic objective political knowledge. Once we have this information, we can simulate what would happen if the electorate's demographics remained unchanged, but all citizens were able to get perfect scores on tests of objective political knowledge. ${ }^{33}$

This proposal avoids the objection from selection bias only if all potential confounders that influence both voting behavior and competence acquisition are observable. But demographic variables

\footnotetext{
${ }^{30}$ Because the objection from selection bias implies this weaker claim, it does not invite Mulligan's response to Estlund's use of the demographic objection ("On the compatibility of epistocracy and public reason").

${ }^{31}$ Brennan, Against Democracy, p. 228.

${ }^{32}$ See also Malcolm, "Epistocracy and Public Interests".

${ }^{33}$ Brennan, Against Democracy, p. 221.
} 
like race, class, gender, and so on are not the only sources of selection bias, as we've already shown. If there are unobserved factors that affect both voting behavior and competence acquisition, then the probability that the average (hypothetical) member of this simulated electorate votes correctly can be lower than the average (actual) democratic voter's probability of voting correctly.

One cannot form a reasonable opinion about the Simulated Oracle without first considering the following question: among a group of people who are all alike with respect to the observable demographic variables that this method controls for, what explains why some of them get perfect scores on the tests of political knowledge while others do not? The answer to that question points one toward the possible confounders or reassures one that there are none. Of the variables implicated in the answer, one must then ask whether they might also influence voting behavior by other causal pathways. A moment's reflection suggests various possibilities. Perhaps the explanation is that some people are more ambitious, intelligent, or resourceful, all qualities that affect career prospects, income, and other links in causal chains that eventually terminate in voting behavior. Perhaps the answer is that some people enjoy accumulating knowledge that confirms their prejudices, or equips them to engage skillfully in public argument, to continue with the story above about differential incentives for acquiring information. Perhaps core personality traits influence both the desire for information and, via other causal pathways, one's political opinions. Any of these possibilities are cause to doubt whether the average (hypothetical) member of the simulated electorate is more likely to vote correctly than the average (actual) democratic voter

Over the last two decades social science has placed increasing emphasis on the importance of research designs and strategies for credibly identifying causal effects. ${ }^{34}$ In no small part, this

34Joshua Angrist and Jörn Pischke, "The Credibility Revolution in Empirical Economics: How Better Research Design is Taking the Con out of Econometrics" Journal of Economic Perspectives 24 (2010): 3-30; Stephen Morgan and Christopher Winship, Counterfactuals and Causal Inference: Methods and Principles for Social Research, second edition (New York: Cambridge University Press, 2014); Cyrus Samii, "Causal Empiricism in Quantitative Research,” The Journal 
is because social scientists are increasingly skeptical of the possibility of observing and measuring all the potential confounders in the typical settings that interest social scientists—such as the effects of political knowledge on voting behavior. Since it cannot account for unobserved (or unobservable) confounders, the Simulated Oracle proposal cannot avoid such skepticism. Defenders of epistocracy should be worried if their core conjecture, the basis for a proposed radical transformation of existing political institutions, is plausible only under assumptions that would struggle to get through peer review at credible social science journals.

Turning now to a second proposal, López-Guerra proposes an "enfranchisement lottery," which Brennan cites approvingly as a version of epistocracy that is immune to the demographic objection. López-Guerra leaves his proposal deliberately indeterminate in its institutional details, offering it as a challenge to certain democratic prejudices and asking his reader to entertain whichever version of the schematic proposal the reader considers most compelling. There are ways of filling in the details so that the proposal does not invite the objection from selection bias, although some people might question whether the resulting implementation really counts as an epistocracy, as opposed to the kind of lottery-based interpretation of democracy that many self-described democrats now defend. Brennan, however, fills in a critical detail that results in an implementation naturally viewed as a form of epistocracy, but also one that is vulnerable to the objection from selection bias.

The first step of the lottery, taken prior to each election, is to select a random sample of the population who alone are eligible to acquire the right to vote. Everyone else is disenfranchised. The members of the random sample — the "pre-voters"- are then invited to participate in a competencebuilding exercise. If they choose to participate, then they become enfranchised. ${ }^{35}$ However, as Brennan reconstructs the proposal, the "pre-voters may then earn the right to vote, but only if they of Politics 78 (2016): 941-955.

${ }^{35}$ López-Guerra, Democracy and Disenfranchisement, chap. 2. 
first participate in and pass certain competence-building exercises."36 The key difference is that Brennan assumes that, to qualify to vote, pre-voters must pass some test of competence, to be administered after the competence-building exercise. To our knowledge, that assumption is absent from López-Guerra's presentation of the idea.

Brennan's addition of the competence test makes all the difference as far as the objection from selection bias is concerned. Assuming the size of the random sample is large enough, that all randomly selected pre-voters choose to participate in the competence-building exercise, and that the average effect of the competence-building exercise is to increase the probability of voting correctly-assuming, in other words, that it merits the name "competence-building exercise"then the probability that the typical pre-voter votes correctly can only be higher than the probability that the typical democratic voter votes correctly. (The second assumption would of course be unjustified if participation were voluntary and uncompensated, but seems reasonable if participation is either compulsory or monetary compensation is sufficiently generous.) There is in this case no bias in who is selected, nor in who is ultimately enfranchised; everyone is equally likely to become enfranchised, and the average voter under this system is indistinguishable, except for their higher level of competence, from the average voter under universal suffrage.

With Brennan's version of the proposal, however, pre-voters who fail a competence test are disenfranchised, so we must ask whether there might be confounders that raise the probability of passing the test and also affect voting behavior by other pathways. It is, again, not hard to think of plausible candidates. Perhaps pre-voters from certain professions or class backgrounds will have an easier time with the test even after everyone undergoes the same competence-building exercise, but will also be biased against voting for the best option by the prejudices characteristic of those social backgrounds. Perhaps partisans and ideologues will be more strongly motivated to learn whatever information is needed to pass the competence-building exercise, because they are more concerned with social status and signaling their political sophistication and moral superiority,

36“Does the Demographic Objection to Epistocracy Succeed?", p. 55, emphasis in original. 
and public validation of being well-informed helps in this regard. And perhaps the agencies that organize the competence-building exercise are not paragons of dispassionate, apolitical neutrality, but instead flesh-and-blood human beings whose own biases creep into the informational briefing materials and the exam, such that pre-voters who share their orientation are both more likely to pass the exam and less likely to vote for the best alternative. Whatever the case may be, Brennan's amendment to López-Guerra's proposal makes it vulnerable to the objection from selection bias.

\section{Conclusion}

Recall the crucial premises in our reconstruction of the argument for the Epistocratic Conjecture:

(1) Being measurably competent increases a person's probability of voting correctly.

(2) Thus measurably competent citizens are more likely to vote correctly than measurably incompetent citizens.

We have shown that the threat of selection bias implies both that the move from (1) to (2) is faulty and that the truth of (2) fundamentally depends on contingent facts about the joint distribution of countless variables that influence voting behavior. The threat of selection bias therefore implies that we have no reason to accept that (2) holds across a wide range of circumstances and, so, no reason to accept epistocrats' conjecture that epistocratic voters are on average more likely to vote correctly than democratic voters. We are thus left without any reason to seriously entertain epistocracy as a practical proposal.

One potential concern is that our objection goes too far, undermining any argument for delegating decision-making to people with special knowledge in any context. Yet surely decisions to approve new medications should be left to panels of medical scientists, choices among design options for new public works should be left to panels of engineers, and so on. ${ }^{37}$ Does the objection

${ }^{37}$ One may also wonder whether our argument is compatible with Dimitri Landa and Ryan 
from selection bias, absurdly, target arguments for these common-sense views?

A decision-making procedure is susceptible to selection bias when two conditions obtain: (a) competence is not distributed as good as randomly within a population, so that competence is systematically correlated with other attributes; (b) these latter attributes plausibly affect a person's decision in a way that counteracts or neutralizes the positive effect of competence on decisionmaking. Putting our point in this way allows us to identify two restrictions on the scope of the objection from selection bias: since (a) and (b) are both necessary, the objection fails to apply if either (a) or (b) fails to obtain. If (a) fails to obtain, then competent individuals will be a representative sample of the population with respect to all attributes except competence. Our discussion of López-Guerra's “enfranchisement lottery” illustrates how a decision-making procedure avoids the objection from selection bias if (a) fails to obtain. Short of a situation in which competence is distributed as good as randomly, we must speculate about, or measure empirically, the strength of its correlation with other attributes affecting the probability of deciding correctly as well as Pevnick's "epistocratic" justification of representative democracy, which appeals to the claim that elected officials, because their actions are more likely to be pivotal and they are held accountable for them, have stronger incentives to acquire relevant competence than ordinary citizens ("Representative Democracy as Defensible Epistocracy," American Political Science Review 114 (2020): 1-13). Provided elections select for individuals who are "at baseline" at least as likely to support good policies as ordinary citizens, or more likely to do so, their claim about elected officials' incentives could justify the conclusion that they are more likely to support good policies than ordinary citizens without inviting the objection from selection bias. It would be analogous in its logic to the following claim: if one recruits people who are at least as healthy as the average member of the general population into a study in which they are provided with incentives to do something that, by assumption, has the effect of making one healthier, then they will end up healthier than the average member of the general population. What is called condition (b) in the next paragraph would fail to hold in this case. 
the magnitude of their effects. Where the case for delegating decision-making authority to people with technical expertise is uncontroversial, it is because there are good grounds for believing this correlation to be weak or these effects to be minimal or benign.

Consider, for example, the technical engineering knowledge needed to evaluate two proposed designs for a new bridge-knowledge that, by assumption, has a positive effect on the probability of selecting the better of the two designs. This knowledge will not be distributed as good as randomly in the population, but it may be that none of the attributes with which it correlates (race, gender, class, etc.) affects the probability that a person would select the better of the two proposals. This case can be represented by a slightly modified version of figure 1, in which the arrow from $A$ to $V$ is absent. In this case, the objection from selection bias has no bite because competence is the only variable that affects decision-making, and it improves decision-making by assumption. Or it might correlate with an attribute, like conscientiousness, which itself has a positive effect on the probability of selecting the best bridge design. Again, the objection from selection bias has no bite. Finally, it could correlate with an attribute that negatively affects the probability of selecting the best proposal. For example, perhaps among the pool of individuals who could be selected to review and decide on the proposals, technical engineering expertise correlates with having some kind of conflict of interest. Where we can control for any such mitigating factors, we rightly take steps to do so-for example, by requiring experts to declare any potential conflicts of interest or excluding those with such conflicts from the selection panel. Where we have reason to believe that we cannot control for mitigating factors, we rightly worry that they might undercut the beneficial effects of expertise.

Politics is importantly different from engineering. When it comes to political decisions, various attributes of a person, beyond just competence and the presence or absence of conflicts of interest, may affect the probability of voting for the best option and, thus, create reasonable doubt that more competent voters would make better decisions. If measurable competence correlates with these attributes, then whether it is best to leave decision-making to competent individuals turns on the 
strength of this correlation and the magnitude of these attributes' effects relative to the positive effect of competence.

At this point, epistocracy's sympathizers might be tempted to define "competence" so that it is just true by definition that more competent voters are more likely to vote correctly. That is, they might reply that epistocratic suffrage rules should be defined as enfranchising all and only those citizens who are most likely to vote correctly. A minor objection is that the resulting scheme would not merit the name "epistocracy" because, as the examples above indicate, the attributes in virtue of which some voters are more likely to vote correctly, in a particular context, need not be knowledge or anything naturally described as an ability. For instance, being biased in favor of a party which, for unrelated reasons, is the best option is not an ability.

A more important problem is that, as we suggested at the outset, this move turns epistocracy into an aspiration rather than a concrete institutional proposal. A concrete proposal requires specifying an observable outcome, such as performance on a certain kind of test or possession of a university degree, as the basis for suffrage. One can identify observable outcomes which, plausibly enough, indicate possession of certain abilities or knowledge that can only serve to increase the probability of voting correctly. But for any such observable outcome, it will always be an open question whether the citizens enfranchised on its basis are on average more likely to vote correctly than those disenfranchised. What is relatively uncontroversial is that certain abilities and forms of knowledge influence the probability of voting correctly_claims, like (1), which posit causal effects. For epistocrats to make such claims without argument and without evidence is fair enough; they seem like as good a starting point as any. What is a matter of controversial speculation is whether citizens who have these abilities and forms of knowledge are on average more likely to vote correctly-claims, like (2), which posit correlation between measurable competence and voting for the best option. One can either define epistocratic suffrage rules in terms of claims like (1), in which case a concrete institutional rule is being proposed and we can readily imagine how to implement it, but the specter of selection bias makes it an open question whether the average 
epistocratic voter would be more likely to vote correctly than the average democratic voter. Or one can define epistocratic suffrage rules in terms of claims like (2), in which case it is trivially true that the average epistocratic voter would be more likely to vote correctly, but it is an open question whether there are any feasible rules that realize what is now just an aspiration. Gerrymandering one's definitions will not circumvent the basic problem that there is no way to determine who is most likely to vote correctly absent controversial assumptions about which options are the correct ones. 